\title{
Sensitizing Effects of Ti Alloying Contents on Damage Behavior of Austenitic Stainless Steel Exposed to Ultrasonic Vibratory Cavitation
}

\author{
J.H. LEE ${ }^{a}$ AND S.J. KIM ${ }^{b, *}$ \\ ${ }^{a}$ Korea Testing \& Research Institute, Key Industry Division, Jongga-ro 15, Ulsan, 44412, Korea \\ ${ }^{b}$ Mokpo National Maritime University, Division of Marine Engineering, \\ Haeyangdaehak-Ro 91 Mokpo-si, Jeollanam-do, 530-729, Korea
}

\begin{abstract}
The cavitation damage characteristics of austenitic stainless steel with different concentrations of Ti were investigated. The microstructure of the alloys was observed with optical microscope to identify its correlation with cavitation resistance. Hardness of the alloys was measured to examine its contribution to cavitation damage. It was found that the microstructure played a more significant role in cavitation damage behavior of austenitic stainless steel with Ti than the hardness. The findings in this study revealed that Ti addition in austenitic stainless steel may present either a beneficial or detrimental effect on cavitation damage behavior, depending on the microstructural characteristics. In particular, Ti content of $1.0 \%$ represented the most deteriorated cavitation characteristics due to the formation of relatively coarse precipitates. Therefore, control of Ti concentration is essential for marine application of austenitic stainless steel.
\end{abstract}

DOI: 10.12693/APhysPolA.129.578

PACS/topics: 47.55.dp

\section{Introduction}

Stainless steel possesses excellent corrosion resistance and mechanical properties and is extensively used in offshore structure, petrochemical plants and power plants where high durability and corrosion resistance are required. Nowadays, modern hydraulic machinery and components made of stainless steel demand a high level of resistance to corrosion and wear since today's modern machines work with high speed and high performance. If the working fluid contains corrosive agents, such as seawater, it is important to take into account effects of cavitation and corrosion [1]. Cavitation is referred as the process of formation and implosion of bubbles in hydraulic system, causing undesirable damage to the components. Cavitation damage occurs in ship's propellers, pump impellers and other conditions, where high velocity liquid flow and pressure drops are encountered. The operating efficiency of the machinery decreases due to cavitation. Development of cavitation mitigation method and cavitation resistant material require a precise knowledge of the mechanism and progress of damage, and the related research is gaining much attention.

Cavitation characteristics and subsequent damage to material are highly affected by the properties of the cavitating liquid, such as flow velocity, viscosity and temperature. Furthermore, mechanical properties and surface characteristics of material are important factors affecting the cavitation erosion resistance. Numerous literatures

*corresponding author; e-mail: ksj@mmu.ac.kr are available on the relation between cavitation resistance and material properties, especially on micro-structural characteristics. Bregliozzi et al. investigated the cavitation erosion behavior of austenitic stainless steels with different grain sizes and found that the grain size has an important effect on cavitation damage behavior [2]. Some investigators evaluated the cavitation erosion of stainless steels with variable chromium and nickel content, confirming that alloying elements and their contents are highly associated with the cavitation resistance of stainless steel [3]. Other researchers examined the cavitation erosion of $\mathrm{Fe}-\mathrm{Mn}-\mathrm{Al}$ alloys, and confirmed the phase of alloy is one of significant factors affecting cavitation damage [4]. The alloying element and subsequent changes on microstructure are implicated in the cavitation damage. Titanium is a strong carbon stabilizer in stainless steel and added for prevention of sensitization which causes localized form of corrosion. Alloying $\mathrm{Ti}$ more than 5 times of carbon contents is known to provide improved resistance against intergranular and pitting corrosion [5]. Since microalloying element such as Ti causes microstructural and mechanical properties, it is essential to control the alloying contents. This paper investigated the microstructural changes of austenitic stainless steel induced by Ti addition and cavitation damage behavior in seawater.

\section{Experimental methods}

Four different stainless steel grade 316 ingots were prepared using a vacuum induction furnace, adding various concentration of $\mathrm{Ti}$ element $(0.25,0.54,0.75$ and $1.00 \mathrm{wt} \%)$. The ingot alloys underwent hot-rolling at $900{ }^{\circ} \mathrm{C}$, followed by water quenching. For cavitation 
erosion test, the rectangular specimen with a dimension of $1 \mathrm{~cm}$ by $1 \mathrm{~cm}$ was prepared and polished by SiC emery papers of up to \#2000 grit to avoid any effects of surface roughness. Table I shows the chemical composition of the specimen.

TABLE I

Chemical composition (\% of weight) of specimens. Contents of Fe is balanced.

\begin{tabular}{c|c|c|c|c|c|c|c|c|c}
\hline \hline & $\mathrm{C}$ & $\mathrm{Si}$ & $\mathrm{Mn}$ & $\mathrm{P}$ & $\mathrm{S}$ & $\mathrm{Ni}$ & $\mathrm{Cr}$ & $\mathrm{Mo}$ & $\mathrm{Ti}$ \\
\hline $\mathrm{Cr}-\mathrm{Ni}-\mathrm{Mo}-0.2 \mathrm{Ti}$ & 0.06 & 0.85 & 1.71 & 0.03 & 0.02 & 12.26 & 17.01 & 2.55 & 0.25 \\
$\mathrm{Cr}-\mathrm{Ni}-\mathrm{Mo}-0.5 \mathrm{Ti}$ & 0.07 & 0.84 & 1.74 & 0.03 & 0.02 & 12.03 & 17.02 & 2.60 & 0.54 \\
$\mathrm{Cr}-\mathrm{Ni}-\mathrm{Mo}-0.7 \mathrm{Ti}$ & 0.07 & 0.87 & 1.71 & 0.03 & 0.01 & 12.86 & 16.98 & 2.57 & 0.75 \\
$\mathrm{Cr}-\mathrm{Ni}-\mathrm{Mo}-1.0 \mathrm{Ti}$ & 0.06 & 0.88 & 1.71 & 0.03 & 0.02 & 12.01 & 17.00 & 2.62 & 1.00
\end{tabular}

To investigate the correlation between microstructure and cavitation characteristics, the specimen was electropolished in $10 \%$ oxalic acid solution applying dc $2 \mathrm{~V}$ for $5 \mathrm{~min}$ and examined in optical microscope. The grain size distribution was investigated by using image analysis software to distinguish different microstructure of the alloy with $\mathrm{Ti}$ concentration. The hardness of the specimen was determined by a micro-Vickers hardness tester using a load of $9.807 \mathrm{~N}$ for a dwell time of $10 \mathrm{~s}$. An average of 15 readings was taken for each hardness value. The degradation of the specimen under cavitation exposure was estimated using a vibratory cavitation erosion apparatus in which cavitation bubbles created by piezoelectric effect act on the surface of the specimen. The cavitation experiment was carried out in natural seawater (temperature controlled at $30^{\circ} \mathrm{C}$ ) by "stationary specimen" method, as specified in ASTM G-32 standard (ultrasonic vibration at $20 \mathrm{kHz}, 30 \mu \mathrm{m}$ of peak-to-peak amplitude). The specimen was positioned to face the center of the vibrating tip of horn with $1 \mathrm{~mm}$ of stand-off distance and exposed to cavitation for $0.5-10 \mathrm{~h}$. The specimen was cleaned in acetone and distilled water, dried and weighed to an accuracy of $0.1 \mathrm{mg}$ before and after the test. The cavitation damage is expressed in terms of mean depth of erosion (MDE) calculated by the following equation:

$$
\operatorname{MDE}(\mu \mathrm{m})=\frac{\Delta W}{10 \rho A},
$$

where $\Delta W$ is weight loss in $\mathrm{mg}, \rho$ is density in $\mathrm{g} / \mathrm{cm}^{3}$ and $A$ is the exposed surface area in $\mathrm{cm}^{2}$. The surface damaged by cavitation was examined by scanning electron microscopy (SEM), and the damage depth measurement and damage morphology was performed with 3D microscope.

\section{Results and discussion}

Table IIa exhibits the microstructure of the specimen, and Table IIb is the graphical representation of Table IIa processed by image analysis software in order to identify grain size distribution of each specimen. Each color in Table IIb represents different classification on basis
TABLE II

Microstructure (a) and grain size distribution (b) of specimens.
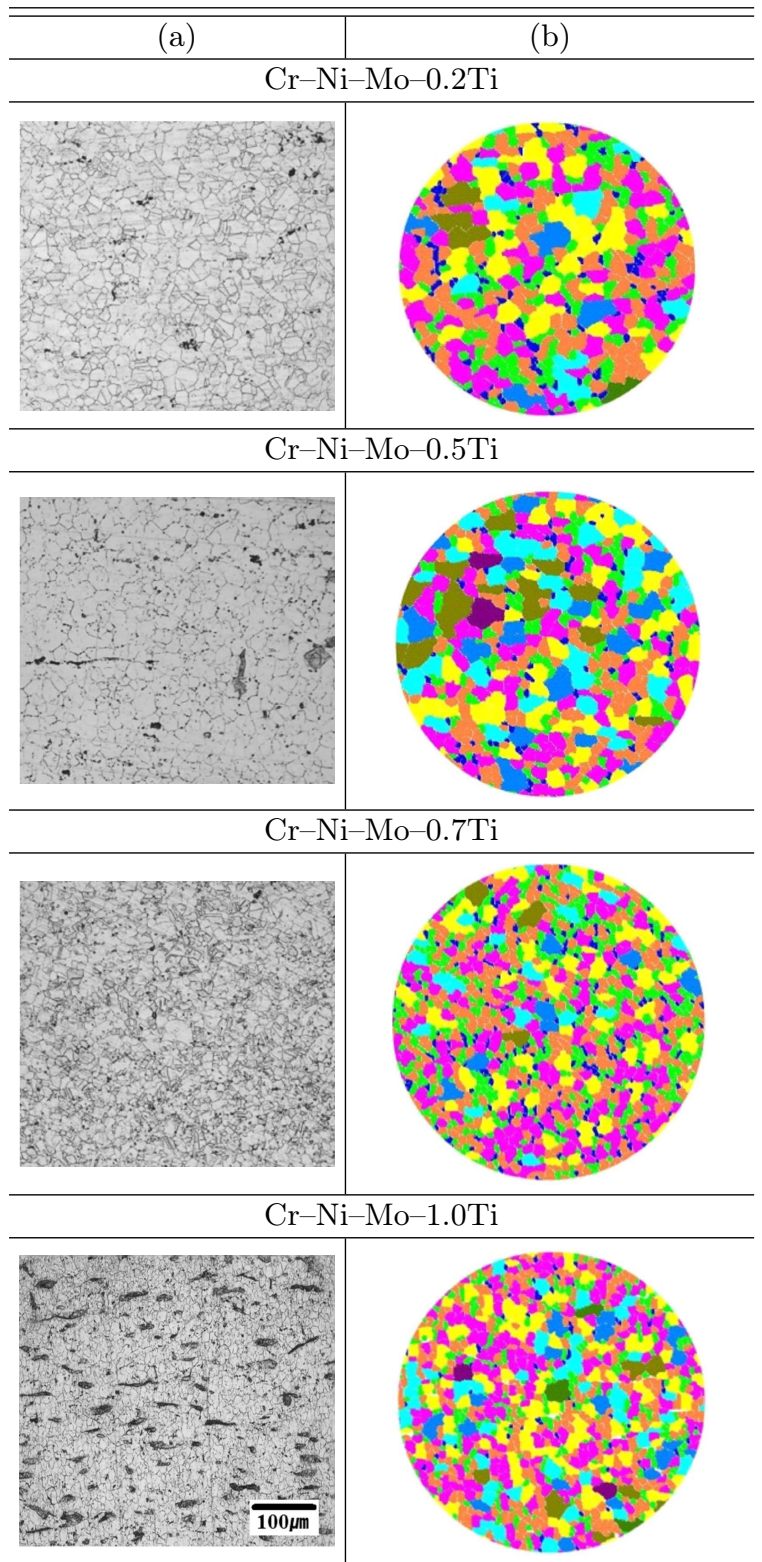

of average grain size in the same range. It is important in the development of cavitation resistant material to establish relationship between microstructure and cavitation characteristics of material. Regardless of $\mathrm{Ti}$ contents, the specimen had austenite phase as the primary phase along with inhomogeneous distribution of secondary phases due to alloying of Ti. In general, austenitic stainless steel with $\mathrm{Ti}$ has $\gamma$-austenite as its primary phase with a small amount of $\alpha$-ferrite phase. In related research, Mo in AISI316Ti stabilizes the Ti carbides and replaces $\mathrm{Cr}$ into carbide and intermetallic compounds, consequently reducing precipitation of Cr-rich carbides [6]. Since the specimens in this study contained more than $2.5 \mathrm{wt} \%$ of Mo, Ti-rich carbides were formed 
predominantly, while the formation of Cr-rich carbides was suppressed. It was observed that the Ti-containing precipitates were finely distributed in $\mathrm{Cr}-\mathrm{Ni}-\mathrm{Mo}-0.2 \mathrm{Ti}$, $\mathrm{Cr}-\mathrm{Ni}-\mathrm{Mo}-0.5 \mathrm{Ti}$ and $\mathrm{Cr}-\mathrm{Ni}-\mathrm{Mo}-0.7 \mathrm{Ti}$ alloy, while relatively large Ti-containing precipitates elongated in rolling direction were observed in $\mathrm{Cr}-\mathrm{Ni}-\mathrm{Mo}-1.0 \mathrm{Ti}$ alloy. In a related research, $\mathrm{Xu}$ et al. classified Ti-containing precipitates in the size range of several to several dozen $\mu \mathrm{m}$ into three types: TiN or duplex $(\mathrm{Al}, \mathrm{Mg}) \mathrm{O} / \mathrm{TiN}, \mathrm{Mo}-$ rich $(\mathrm{Ti}, \mathrm{Mo}) \mathrm{C}$ and $\mathrm{Ti}(\mathrm{N}, \mathrm{C})$ precipitates [7]. Ti is well known as a grain refining element in stainless steel, and in this study the grain size of the specimen was roughly decreased with increasing $\mathrm{Ti}$ contents.

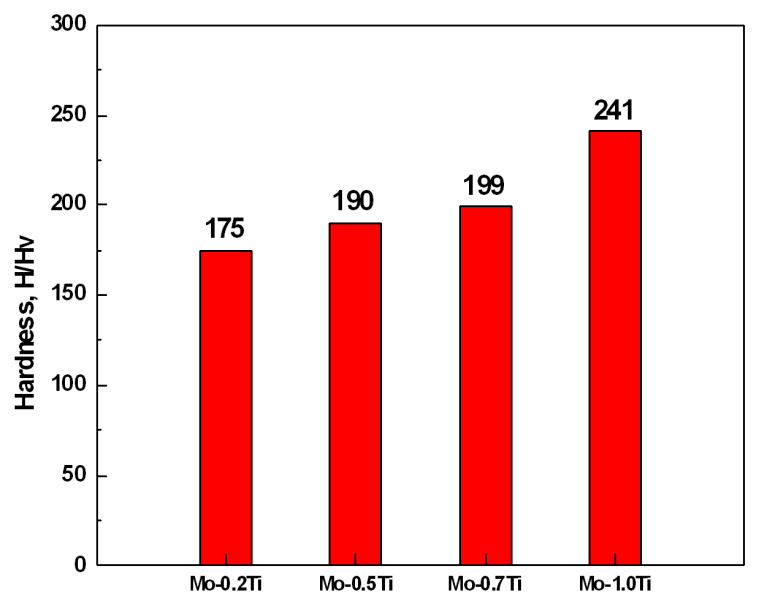

Fig. 1. Hardness value of stainless steel with Ti concentration.

Figure 1 compares the hardness values with different Ti concentration measured prior to cavitation experiment. The hardness measurement showed an increasing trend in hardness with increasing Ti content, and particularly $\mathrm{CrNi}-\mathrm{Mo}-1.0 \mathrm{Ti}$ alloy exhibited the highest hardness value of $241 \mathrm{Hv}$. The improvement in hardness by $\mathrm{Ti}$ addition is believed to be attributable to not only grain refining effect but also suppression of dislocations by the presence of the precipitates. Many investigators have tried to correlate the hardness value and cavitation resistance, and it is now generally accepted that the hardness of material is the most affecting factor on cavitation resistance, as compared to other mechanical properties. In a relevant study, Hattori et al. constructed extensive experimental data on the cavitation erosion of commercial alloys [8]. They proposed the normalized erosion resistance expressed against the hardness. Recently, some researchers investigated the electrochemical responses to degradation of the surface layer nanomechanical properties of stainless steels in $3.5 \% \mathrm{NaCl}$ solution under cavitation. They reported that the cumulative mass loss was found to increase with decreasing nanomechanical property expressed in nanohardness/nanoelastic modulus and that the electrochemical corrosion of stainless steels under cavitation was accelerated as a result of degradation of nanomechanical properties of the surface layer [9].

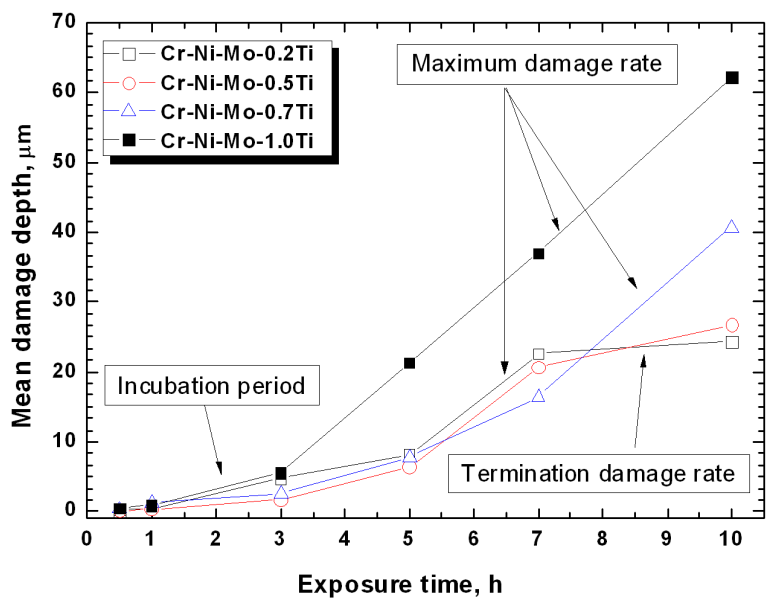

Fig. 2. Mean erosion depth with cavitation time in seawater.

Figure 2 represents the mean erosion depth of the specimens with exposure time to cavitation. Generally, four of specimens had incubation period in the initial stage of cavitation experiment, but different damage-time patterns were observed over time for each specimen. The incubation period in the early stage of cavitation experiment is thought to represent the accumulation of plastic deformation, and negligible weight loss is observed. It is generally agreed that the presence of such incubation period in austenitic stainless steel is due to martensitic transformation of the austenite phase by shock energy from cavities, and this absorbs the collapse energy from cavities, consequently increasing cavitation resistance [10]. Until $3 \mathrm{~h}$ of cavitation exposure, there was no distinct difference in mean erosion depth between the specimens; however, since then $\mathrm{Cr}-\mathrm{Ni}-\mathrm{Mo}-1.0 \mathrm{Ti}$ alloy exhibited maximum damage depth of $62.1 \mu \mathrm{m}$. The $\mathrm{Cr}-\mathrm{Ni}-$ Mo-0.7Ti alloy maintained a relatively low mean erosion depth until $7 \mathrm{~h}$ of cavitation, and then showed a rapid increase until the end of the experiment. It is notable that $\mathrm{Cr}-\mathrm{Ni}-\mathrm{Mo}-0.2 \mathrm{Ti}$ and $\mathrm{Cr}-\mathrm{Ni}-\mathrm{Mo}-0.5 \mathrm{Ti}$ alloy reached the maximum erosion rate at $7 \mathrm{~h}$, but after that time the rate was beginning to decline, thereafter showing termination damage rate from $7 \mathrm{~h}$. In the case of $\mathrm{Cr}-\mathrm{Ni}-\mathrm{Mo}-1.0 \mathrm{Ti}$ alloy, the damage depth showed a rapid increasing trend after only $3 \mathrm{~h}$ of experiment. The exposure time to reach a mean erosion depth of $50 \mu \mathrm{m}$ was observed only in $\mathrm{Cr}-\mathrm{Ni}-\mathrm{Mo}-1.0 \mathrm{Ti}$ alloy, which showed the lowest cavitation resistance among the specimens. It is commonly assumed that carbides in stainless steel can exert beneficial effects on cavitation resistance. It is reported that finer carbide distribution in the matrix enhances cavitation resistance [11] whereas coarse morphology of carbides is responsible for deterioration of cavitation resistance [12]. As compared to $\mathrm{Cr}-\mathrm{Ni}-\mathrm{Mo}-1.0 \mathrm{Ti}$ alloy, all other three alloys represented relatively high cavitation resistance, possibly owing to the fine distribution of the carbides. In spite of the highest hardness, $\mathrm{Cr}-\mathrm{Ni}-\mathrm{Mo}-1.0 \mathrm{Ti}$ represented poor cavitation resistance, and this is believed 
to be due to repetitive application of shock energy from cavities, giving rise to brittle fracture developed in the interface between the carbide and matrix [13].

TABLE III

SEM images of damaged surface after cavitation experiment.

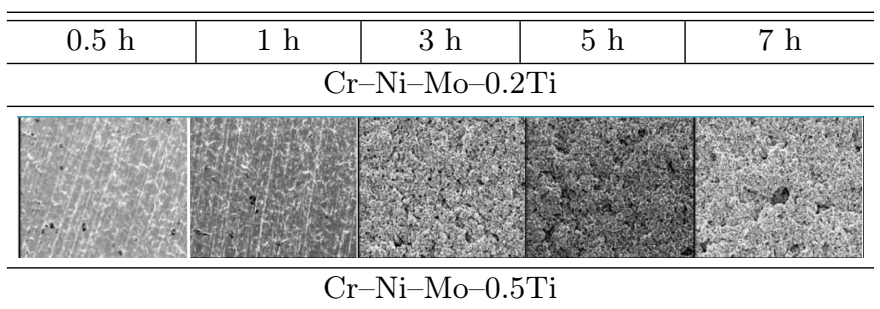
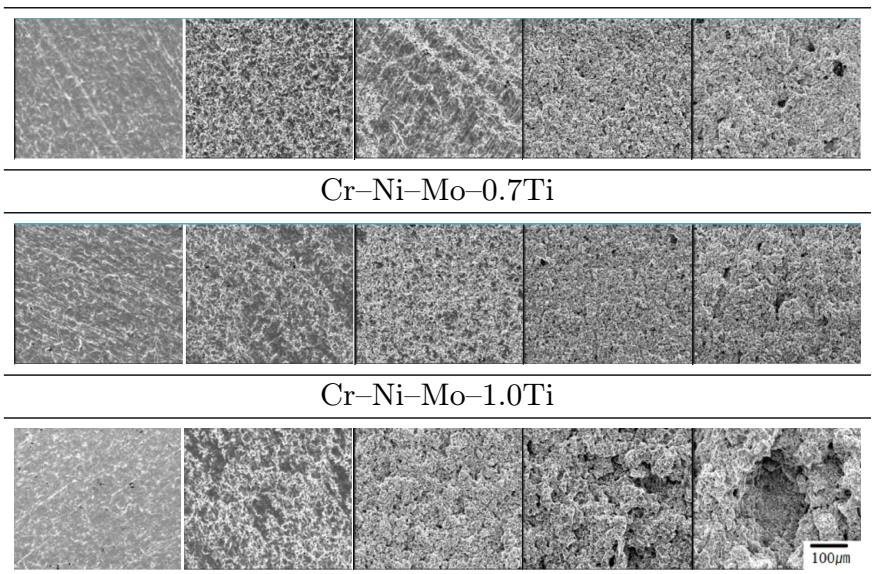

Table III reveals SEM images for the damaged area with $\mathrm{Ti}$ content and cavitation time. Regardless of $\mathrm{Ti}$ content, all specimens showed similar damage progression and morphology. The specimens after $1 \mathrm{~h}$ of cavitation had several micropits, which were later propagated into larger pits with increasing cavitation time. AbouelKasem et al. reported that pit formation is one of the characteristics of the incubation period, and the formation and development of pits are acknowledged to be a complex process [14]. In their study, pits can be divided into two types, based on their shape and origination, namely microjet-pits and shockwave-pits. The microjetpits, which are formed by microjet from cavities, are randomly distributed with irregular shape and are small in size (several $\mu \mathrm{m}$ ), while the shockwave-pits are originated from plastic flow, having considerably larger size (several dozen $\mu \mathrm{m}$ ) than the microjet-pits. The microjet-pits are frequently observed in cavitation resistant materials such as stainless steel, and the shockwave-pits in ductile materials such as aluminum and copper alloys. In this study, the microjet-pits were mainly observed at all specimens after $0.5 \mathrm{~h}$ of cavitation experiment. It is generally acknowledged that the cavitation behavior of stainless steels significantly varies with different microstructures. In the case of austenitic stainless steels with austenite single phase, plastic deformation occurs during the beginning of cavitation-erosion process and slip lines appear in the austenite grains, and then material is removed from slip lines in austenite grains by ductile fracture [15]. Bregliozzi et al. distinguished cavitation erosion process of austenitic stainless steel into three stages: (1) initiation of cavitation attack at the grain boundaries and slip bands, resulting in the formation of surface undulations, (2) crack growth from the defects which represent origins of stress concentration, (3) material removal by ductile fracture mechanism [2]. The result of the present study is well agreed with the finding reported by Bregliozzi et al., irrespective of Ti contents. It was found that a long duration of cavitation above $3 \mathrm{~h}$ caused the damage to create small pits, which would later form crater-type pit with further cavitation $(5-7 \mathrm{~h})$.

Table IV presents the morphology and profile for damaged surface by using 3D microscope after $7 \mathrm{~h}$ of cavitation experiment. It was found that only slight damage occurred to $\mathrm{Cr}-\mathrm{Ni}-\mathrm{Mo}-0.5 \mathrm{Ti}$ and $\mathrm{Cr}-\mathrm{Ni}-\mathrm{Mo}-0.7 \mathrm{Ti}$ alloy, while $\mathrm{Cr}-\mathrm{Ni}-\mathrm{Mo}-0.2 \mathrm{Ti}$ and $\mathrm{Cr}-\mathrm{Ni}-\mathrm{Mo}-1.0 \mathrm{Ti}$ alloy suffered severe damage with marked undulation. Most notably, $\mathrm{Cr}-\mathrm{Ni}-\mathrm{Mo}-1.0 \mathrm{Ti}$ alloy had irregularly shaped crater pits with the size of about $400 \mu \mathrm{m}$ in width. This damage type happens due to the coalescence of pits, giving rise to elimination of grains [15]. The roughness for $\mathrm{Cr}-\mathrm{Ni}-\mathrm{Mo}-0.5 \mathrm{Ti}$ and $\mathrm{Cr}-\mathrm{Ni}-\mathrm{Mo}-0.7 \mathrm{Ti}$ alloy were determined to be $0.5 \mu \mathrm{m}$ and $\mathrm{Cr}-\mathrm{Ni}-\mathrm{Mo}-1.0 \mathrm{Ti}$ to be $1.3 \mu \mathrm{m}$, showing an agreement with surface roughness of some metallic materials in vibratory cavitation-erosion [16]. They observed that the roughness increases linearly during plastic deformation due to bubble collapse in an initial stage, but slight deviation is produced if the surface is work-hardened, making it more resistant to plastic deformation. When cavitation-erosion experiment starts, material removal continues to increase the roughness. Finally, steady-state stage is reached and the roughness remains constant because of a self-regulating process, in which the asperities and protruding parts are preferentially damaged.

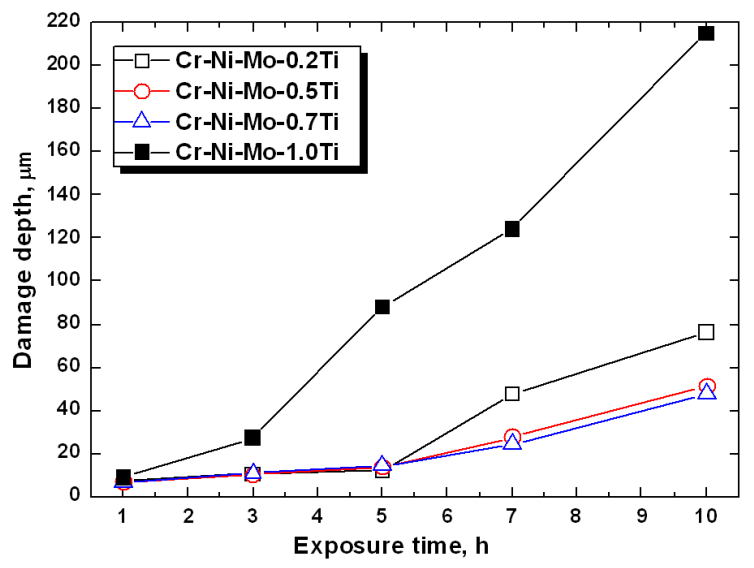

Fig. 3. Trend of damage depth development for specimens measured by 3D microscope.

Figure 3 compares the damage depth measurements after cavitation. The values represent empirical values which are the maximum depth of damage produced 
TABLE IV

Morphologies and profiles (below) for surface after cavitation experiment during $7 \mathrm{~h}$.

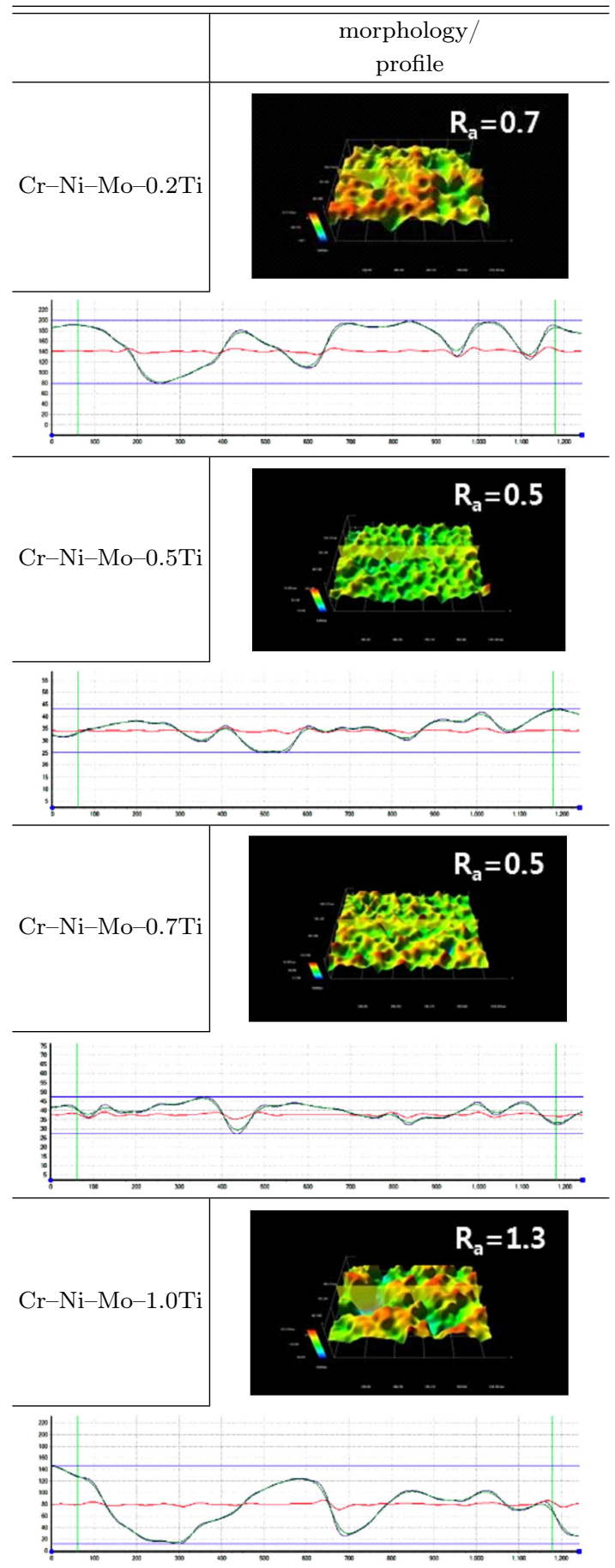

by cavitation-erosion process, in contrast with the MDE (Fig. 2) which is calculated gravimetric method. The maximum damage depth had a tendency to increase with time, and this trend agreed with those with measurement of MDE. The $\mathrm{Cr}-\mathrm{Ni}-\mathrm{Mo}-1.0 \mathrm{Ti}$ alloy showed the highest damage depth with $214.8 \mu \mathrm{m}$, followed by $\mathrm{Cr}-\mathrm{Ni}-$ $\mathrm{Mo}-0.2 \mathrm{Ti}$ with $76.3 \mu \mathrm{m}$, and both $\mathrm{Cr}-\mathrm{Ni}-\mathrm{Mo}-0.5 \mathrm{Ti}$ and
$\mathrm{Cr}-\mathrm{Ni}-\mathrm{Mo}-0.7 \mathrm{Ti}$ alloy showed the lowest values. In this study, cavitation experiment was carried out in seawater solution, and the cause of pit depth growth can be considered in terms of synergistic effect of cavitation and corrosion [17]. The shock induced by cavity collapse as well as chloride ions in seawater exert a detrimental influence on the surface of stainless steel, leading to breakdown of the passive film. Kwok et al. investigated the synergistic effect of cavitation-erosion and corrosion of various engineering alloys in $3.5 \% \mathrm{NaCl}$ solution. According to their study, stainless steels only suffered pure mechanical erosion under cavitation, and thus synergism by corrosion plays a negligible role for stainless steels [18]. In this study, the growth of micropit into crater-shaped damage is considered to be due to shockwave from micro-jet impact and collapse of bubble clustering, thereby mechanical erosion being prevalent during cavitation-erosion process, rather than synergism of cavitation erosion and corrosion [15].

\section{Conclusion}

1. Besides the austenite phase, Ti-containing precipitates were observed, and these increased in size with increasing $\mathrm{Ti}$ contents. The grain refining effect was found with increasing Ti contents.

2. The $\mathrm{Cr}-\mathrm{Ni}-\mathrm{Mo}-1.0 \mathrm{Ti}$ alloy with the highest hardness showed the least cavitation resistance. This may be attributed to concentration of stress from cavitation shockwave induced in the interface between the matrix phase and precipitates, consequently leading to brittle fracture.

3. In the cavitation damage of stainless steel, four stages are distinguished: formation of microjet pits, plastic deformation, grain removal, pit coalescence to form craters.

4. Ti content in austenitic stainless steel significantly influenced susceptibility to cavitation damage. Considering this, it is important in developing stainless steel to control and determine appropriate amount of Ti addition.

\section{References}

[1] R.J.K. Wood, S.A. Fry, J. Fluids Eng. 111, 271 (1989).

[2] G. Bregliozzi, A.D. Schino, S.I.U. Ahmed, J.M. Kenny, H. Haefke, Wear 258, 503 (2005).

[3] A. Karabenciov, A.D. Jurchela, I. Bordeasu, M. Popoviciu, N. Birau, A. Lustyan, in: 25th IAHR Symp. on Hydraulic Machinery and Systems, Ed. R.S. Resiga, IOP Publishing, Timisoara 2010, p. 1755.

[4] S.C. Chang, W.H. Weng, H.C. Chen, S.J. Lin, P.C.K. Chung, Wear 181, 511 (1995).

[5] A. Pardo, M.C. Merino, A.E. Coy, F. Viejo, M. Carboneras, R. Arraval, Acta Mater. 55, 2239 (2007). 
[6] J. Brnic, G. Turkalj, M. Canadija, D. Lanc, J. Construct. Steel Res. 67, 1948 (2011).

[7] S. Xu, X.Q. Wu, E.H. Han, W. Ke, Y. Katada, Mater. Sci. Eng. A 490, 16 (2008).

[8] S. Hattori, R. Ishikura, Q. Zhang, Wear 257, 1022 (2004).

[9] X. Yong, D. Li, H. Shen, Master. Chem. Phys. 139, 290 (2013).

[10] M.C. Park, K.N. Kim, G.S. Shin, S.J. Kim, Wear 274, 28 (2012).

[11] M.G.D.V. Cuppari, F. Wischnowski, D.K. Tanaka, A. Sinatora, Wear 225, 517 (1999).

[12] M.G.D.V. Cuppari, R.M. Souza, A. Sinatora, Wear 258, 596 (2005).
[13] A.A. Kasem, A.E.E. Deen, K.M. Emara, S.M. Ahmed, J. Tribol. 131, 031605 (2009).

[14] W. Liu, Y.G. Zheng, C.S. Liu, Z.M. Yao, W. Ke, Wear 254, 713 (2003).

[15] S.A. Karrab, M.A. Moheim, M.S. Aboraia, S.M. Ahmed, J. Tribol. 134, 011602 (2012).

[16] K.Y. Chiu, F.T. Cheng, H.C. Man, Ultrasonics 43, 713 (2005).

[17] R.J.K. Wood, S.P. Hutton, Wear 140, 387 (1990).

[18] C.T. Kwok, F.T. Cheng, H.C. Man, Mater. Sci. Eng. A 290, 145 (2000). 